\title{
Cytoplasmic VDR expression as an independent risk factor for ovarian cancer
}

\author{
Bastian Czogalla ${ }^{1}$ - Eileen Deuster ${ }^{1} \cdot$ Yue Liao $^{1} \cdot$ Doris Mayr $^{2} \cdot$ Elisa Schmoeckel ${ }^{2} \cdot$ Cornelia Sattler $^{1}$. \\ Thomas Kolben $^{1}$ - Anna Hester ${ }^{1}$. Sophie Fürst ${ }^{1}$. Alexander Burges ${ }^{1} \cdot$ Sven Mahner $^{1}$. Udo Jeschke ${ }^{1,3}$. Fabian Trillsch ${ }^{1}$
}

Accepted: 13 June 2020 / Published online: 22 June 2020

(c) The Author(s) 2020

\begin{abstract}
The vitamin D receptor (VDR), primarily known as a crucial mediator of calcium homeostasis and metabolism, has been shown to play a significant role in various cancer entities. Previous studies have focused on vitamin D and its receptor in gynecological cancers, noting that the receptor is upregulated in epithelial ovarian cancer (EOC). The aim of this study is to analyze the prognostic impact of VDR and its functional significance in ovarian cancer. Through immunohistochemistry, VDR staining was examined in 156 ovarian cancer samples. Evaluation of VDR staining was conducted in the nucleus and the cytoplasm using the semi-quantitative immunoreactive score, and the scores were classified into high- and low-level expressions. Expression levels were correlated with clinical and pathological parameters as well as with overall survival to assess for prognostic impact. Differences in cytoplasmic VDR expression were identified between the histological subtypes $(p=0.001)$. Serous, clear cell, and endometrioid subtypes showed the highest staining, while the mucinous subtype showed the lowest. Cytoplasmic VDR correlated with higher FIGO stage $(p=0.013 ; C c=0.203)$, positive lymph node status $(p=0.023 ; C c=0.236)$, high-grade serous histology $(p=0.000 ; C c=0.298)$ and grading from the distinct histological subtypes $(p=0.006 ; C c=-0.225)$. Nuclear VDR did not correlate with clinicopathological data. High cytoplasmic expression of VDR was associated with impaired overall survival (HR 2.218, 32.5 months vs. median not reached; $p<0.001$ ) and was confirmed as a statistically independent prognostic factor in the Cox regression multivariate analysis. Additional knowledge of VDR as a biomarker and its interactions within the mitogen-activated protein kinase (MAPK) signaling pathway could potentially improve the prognosis of therapeutic approaches for specific subgroups in EOC.
\end{abstract}

Keywords VDR $\cdot$ Vitamin D $\cdot$ Ovarian cancer $\cdot$ Risk factor $\cdot$ Immunohistochemistry

$\begin{array}{ll}\text { Abbreviations } \\ \text { Cc } & \text { Correlation coefficient } \\ \text { CI } & \text { Confidence interval } \\ \text { EMT } & \text { Epithelial-mesenchymal transition } \\ \text { EOC } & \text { Epithelial ovarian cancer } \\ \text { ERK } & \text { Extracellular-signal-regulated kinase } \\ \text { FFPE } & \text { Formalin fixed and paraffin embedded }\end{array}$

Bastian Czogalla

Bastian.Czogalla@med.uni-muenchen.de

1 Department of Obstetrics and Gynecology, University Hospital, LMU Munich, Marchioninistr 15, 81377 Munich, Germany

2 Institute of Pathology, Faculty of Medicine, LMU Munich, Munich, Germany

3 Department of Obstetrics and Gynecology, University Hospital Augsburg, Augsburg, Germany
FIGO Fédération Internationale de Gynécologie et d'Obstétrique

IRS Immunoreactive score

MAPK Mitogen-activated protein kinase

OS Overall survival

SD Standard deviation

VDR Vitamin D receptor VDR

VDRE Vitamin D response element

WHO Word Health Organization

\section{Introduction}

Ovarian cancer is one of the most lethal tumor entities (Siegel et al. 2019). Insufficient screening methods and rising resistances to chemotherapy over the clinical course further contribute to the relatively low 5-year survival rate of around 45\% (Baldwin et al. 2012; Siegel et al. 2019). 
Recommended therapy consists of cytoreductive surgery followed by adjuvant platinum-based chemotherapy combined with anti-angiogenic agents or followed by polyADP-ribose-polymerase inhibitors. To date, most reliable prognostic factors include the presence of residual disease after initial debulking surgery, the International Federation of Gynecology and Obstetrics (FIGO) stage, ascites volume, patient age, and histological subtype (Dembo et al. 1990; Vergote et al. 2001; Aletti et al. 2006; du Bois et al. 2009). However, widely accepted prognostic biomarkers are missing. Histologically, epithelial ovarian cancer (EOC) is classified into five main subtypes: high-grade serous, low-grade serous, mucinous, endometrioid, and clear cell histology, being distinguished in terms of phenotype, molecular background, and etiology (Kossaï et al. 2018). Considering the heterogeneity of ovarian cancer appears crucial for developing new prognostic and therapeutic strategies.

The VDR, as the receptor of the fat-soluble steroid vitamin $\mathrm{D}$, known as $1 \mathrm{a}, 25(\mathrm{OH})_{2} \mathrm{D}_{3}$ or calcitriol, belongs to the superfamily of nuclear receptors. VDR regulates gene expression by binding to target genes with promoters containing a vitamin D response element (VDRE). VDR is a crucial mediator in calcium homeostasis and metabolism, inflammation, insulin-like growth factor signaling, and estrogen-related pathways and was identified in 30 different tissues (Valdivielso and Fernandez 2006; Holick and Chen 2008).

In recent years, increasing evidence suggests that vitamin $\mathrm{D}$ and VDR play a pivotal role in gynecological cancers (Deuster et al. 2017). VDR expression is increased in ovarian cancer and is associated with altered cancer cell proliferation in an interplay with other growth-stimulating factors like androgens (Ahonen et al. 2000; Villena-Heinsen et al. 2002; Friedrich et al. 2003; Anderson et al. 2006).

According to the increasing understanding of VDR`s role in ovarian cancer biology, expression analysis of VDR in different histological subtypes and of its correlation with survival was the primary aim in the current study.

\section{Materials and methods}

\section{Patients and specimens}

Ovarian cancer samples from 156 patients who underwent surgery for EOC at the Department of Obstetrics and Gynecology, Ludwig-Maximilian's-University Munich from 1990 to 2002, were examined in this study. Clinical data were collected from the patients' charts and followup data obtained from the Munich Cancer Registry. All specimens had been formalin fixed and paraffin embedded (FFPE). Patients with benign or borderline tumors were excluded and no patients had received neoadjuvant chemotherapy. Histological subtype and grading were determined by specialists at the Department of Pathology, Ludwig-Maximilian-University Munich. The staging was performed according to the WHO and FIGO Classification (2014). The clinicopathologic characteristics of the analyzed ovarian cancer patients are listed in Table 1.

Table 1 Clinicopathologic characteristics of the ovarian cancer patients

\begin{tabular}{|c|c|c|}
\hline Clinicopathologic parameters & $n$ & Percentage $(\%)$ \\
\hline \multicolumn{3}{|l|}{ Histology } \\
\hline Serous & 110 & 70.5 \\
\hline Clear cell & 12 & 7.7 \\
\hline Endometrioid & 21 & 13.5 \\
\hline Mucinous & 13 & 8.3 \\
\hline \multicolumn{3}{|l|}{ Primary tumor expansion } \\
\hline TX & 1 & 0.6 \\
\hline $\mathrm{T} 1$ & 40 & 25.6 \\
\hline $\mathrm{T} 2$ & 18 & 11.5 \\
\hline $\mathrm{T} 3$ & 97 & 62.3 \\
\hline \multicolumn{3}{|l|}{ Nodal status } \\
\hline $\mathrm{pNX}$ & 61 & 39.1 \\
\hline pNO & 43 & 27.6 \\
\hline $\mathrm{pN} 1$ & 52 & 33.3 \\
\hline \multicolumn{3}{|l|}{ Distant metastasis } \\
\hline $\mathrm{pMX}$ & 147 & 94.2 \\
\hline pM0 & 3 & 1.9 \\
\hline pM1 & 6 & 3.8 \\
\hline \multicolumn{3}{|l|}{ Grading serous } \\
\hline Low & 24 & 21.8 \\
\hline High & 80 & 72.7 \\
\hline \multicolumn{3}{|l|}{ Grading endometrioid } \\
\hline G1 & 6 & 28.6 \\
\hline $\mathrm{G} 2$ & 5 & 23.8 \\
\hline G3 & 8 & 38.1 \\
\hline \multicolumn{3}{|l|}{ Grading mucinous } \\
\hline G1 & 6 & 46.2 \\
\hline $\mathrm{G} 2$ & 6 & 46.2 \\
\hline G3 & 0 & 0 \\
\hline \multicolumn{3}{|l|}{ Grading clear cell } \\
\hline G3 & 12 & 100.0 \\
\hline \multicolumn{3}{|l|}{ FIGO } \\
\hline I & 35 & 22.4 \\
\hline II & 10 & 6.4 \\
\hline III & 103 & 66.0 \\
\hline IV & 3 & 1.9 \\
\hline \multicolumn{3}{|l|}{ Age } \\
\hline$\leq 60$ years & 83 & 53.2 \\
\hline$>60$ years & 73 & 46.8 \\
\hline
\end{tabular}




\section{Ethical approval}

The Ethics Committee of the Ludwig-Maximilians-University, Munich, Germany, approved this study (approval numbers 227-09 and 18-392). All tissue samples utilized for this investigation were collected from material from the archives of the Department of Obstetrics and Gynecology, University Hospital, LMU Munich, Munich, Germany, having initially been used for pathological diagnostics. The diagnostic procedures were concluded before the current study was conducted. During the analysis, the observers were fully blinded for patients' data.

\section{Immunohistochemistry}

Immunohistochemistry was completed as earlier outlined by our laboratory (Scholz et al. 2012). For the detection of VDR, FFPE tissue sections were dewaxed with xylol for $20 \mathrm{~min}$, and later dehydrated in ascending concentrations of alcohol (70-100\%). Afterward, they were exposed for epitope retrieval for $10 \mathrm{~min}$ in a pressure cooker using sodium citrate buffer ( $\mathrm{pH}$ 6.0) holding $0.1 \mathrm{M}$ citric acid and $0.1 \mathrm{M}$ sodium citrate in distilled water. After cooling, the slides were cleaned in PBS twice. Endogenous peroxidase activity was quenched by dipping in 3\% hydrogen peroxide (Merck, Darmstadt, Germany) and in methanol for $20 \mathrm{~min}$. Non-specific binding of the primary antibodies was blocked by incubating the sections with "diluted normal serum" (10 ml PBS containing $150 \mu \mathrm{l}$ horse serum; Vector Laboratories, CA) for $20 \mathrm{~min}$ at room temperature. Then, slides were incubated with the primary antibody [anti-vitamin D receptor antibody, mouse IgG, monoclonal, Serotec, Puchheim, Germany, clone 2F4 (MCA3543Z)] at room temperature for $60 \mathrm{~min}$. After washing with PBS, slides were incubated in diluted biotinylated anti-serum secondary antibody $(10 \mathrm{ml}$ PBS containing $50 \mu \mathrm{l}$ horse serum, Vector Laboratories, CA) for $30 \mathrm{~min}$ at room temperature. Following incubation with the avidin-biotin-peroxidase complex (diluted in $10 \mathrm{ml}$ PBS, Vector Laboratories, CA) for $30 \mathrm{~min}$ and repeated PBS washing, visualization was conducted using substrate and chromagen 3,3'-diaminobenzidine (DAB; Dako, Glostrup, Denmark, catalog number K3468) for 8-10 min. Slides were then counterstained with Mayer's acidic hematoxylin (Waldeck-Chroma, Münster, Germany, catalog number 2E-038) and dehydrated in an ascending series of alcohol followed by xylol. Negative and positive controls were employed to assess the specificity of the immunoreactions. Negative controls (colored in blue) were conducted in placental tissue by the replacement of the primary antibodies by speciesspecific (rabbit) isotype control antibodies (Dako, Glostrup, Denmark). For positive control, placental, vaginal and intestinal tissues were utilized.

\section{Staining evaluation}

Specific VDR immunohistochemically staining reaction was observed in the nuclei and cytoplasm of the cells. The strength and distribution pattern of VDR staining was evaluated using the semi-quantitative immunoreactive score (IR score, Remmele's score). To obtain the IR score result, the optional staining intensity $(0=$ no, $1=$ weak, $2=$ moderate, and $3=$ strong staining) and the percentage of positive stained cells ( $0=$ no staining, $1 \leq 10 \%$ of the cells, $2=11-50 \%$ of the cells, $3=51-80 \%$ of the cells and $4 \geq 81 \%$ ) were multiplied. In all $156(100 \%)$ EOC tissue samples, VDR staining was successfully performed. Cutoff scores for the IR scores were selected for the cytoplasmic VDR staining, taking into account the distribution pattern of IR scores in the collective. Cytoplasmic VDR staining was considered as low with IRS $0-2$ and as high with IRS $>2$.

For analyzing the images, the light microscope "Immunohistochemistry Type 307-148.001 512 686" by Leitz (Wetzlar, Germany) was used. The camera was produced by Fissler (IHCamera 3CCD Colour Video Camera). For image acquisition, the software "Discuss Version 4,602,017-\#233 (Carl C. Hilgers Technical Office) was used. Image bit depth: $24 \mathrm{~mm}$; time and space resolution data: $760+574$ pixel.

\section{Statistical analysis}

SPSS 25.0 (v25, IBM, Armonk, New York) was used for statistical analysis. The distribution of clinical-pathological variables was assessed with the Chi-square test. The Mann-Whitney $U$ test was utilized to compare IR scores of VDR between different clinical and pathological subgroups. Correlations between findings of immunohistochemical staining were measured using Spearman's analysis. Through Kaplan-Meier (log-rank) estimates, survival times were analyzed. To identify an appropriate cutoff, the ROC curve was drawn, which is considered as one of the most reliable methods for cutoff point selection. In this context, the ROC curve is a plot representing sensitivity on the $y$-axis and (1-specificity) on the $\mathrm{x}$-axis (Nakas et al. 2010). Consecutively, the Youden index, defined as the maximum (sensitivity + specificity-1) (Youden 1950), was used to find the optimal cutoff maximizing the sum of sensitivity and specificity (Fluss et al. 2005; Perkins and Schisterman 2006). For multivariate analyses, a Cox-regression model was used. $p$ values less than 0.05 were considered to be significant. 


\section{Results}

\section{VDR expression correlates with clinical and pathological data}

The clinicopathologic characteristics of the analyzed ovarian cancer patients are listed in Table 1 . Out of 156 successfully stained ovarian cancer specimens, 153 (98\%) showed positive nuclear VDR expression. In the cytoplasm, 154 (99\%) cases were VDR positive. Median (range) immunoreactivity scores (IRS) for VDR in nuclei and cytoplasm were $3(0.9)$ and $3(0.8)$, respectively.

Cytoplasmic VDR staining differed in the histological subtypes $(p=0.001)$ : a high cytoplasmic VDR expression was found in serous, clear cell, and endometrioid histological subtypes, and a low VDR expression in the mucinous subtype (Fig. 1). In comparison, nuclear VDR expression did not show a significant difference between the histological subtypes $(p>0.05)$.

VDR expression displayed correlations to clinical and pathological data (Table 2). A positive correlation was observed between high cytoplasmic VDR staining and positive lymph node status ( $p=0.023 ; C c=0.236)$ as well as with a higher FIGO stage ( $p=0.013 ; C c=0.203)$. High cytoplasmic VDR staining correlated with high-grade serous histology ( $p=0.000 ; C c=0.298)$, as well as with grading from the other histologic subtypes ( $p=0.006 ; C c=-0.225$ ). In the nucleus, VDR does not correlate with clinicopathological data. Nuclear VDR and cytoplasmic VDR expression were observed not to correlate with each other $(p=0.070$; $C c=0.147)$.

\section{High cytoplasmic VDR expression is associated with impaired overall survival}

The median age of the patients was 58.7 [standard deviation (SD) 31.4] years, with a range of 31-88 years. The median follow-up OS of the EOC patients was 34.4 (SD 57.8) months. Cytoplasmic VDR expression was significantly associated with a shorter OS (Fig. 2, 32.5 months vs. median not reached; $p<0.001$ ).

\section{Cytoplasmic VDR and clinical/pathological parameters are independent prognostic factors}

In a cox regression multivariate analysis of the present cohort with established prognostic markers, cytoplasmic VDR expression proved to be a statistically independent prognostic factor (HR 2.218, $p=0.025$ ), as well as cancer grading (HR 1.604, $p<0.001$ ), FIGO stage (HR 1.947, $p<0.001)$ and patient's age (HR 1.628, $p=0.019)$ (Table 3) were proved independent factors. Conversely, the prognostic impact of histological subtypes was not confirmed to be of independent significance.

\section{Discussion}

This present study focused on VDR expression in different histologic subtypes of EOC and its correlation with clinicopathological parameters. Patients with an increased cytoplasmic VDR expression were confirmed to have a significantly impaired OS. Moreover, cytoplasmic VDR expression was identified as an independent prognostic factor for OS; therefore, these results suggest a functional role of VDR in ovarian cancerogenesis, which merits further investigations.

VDR has been traditionally considered as the nuclear receptor of vitamin $\mathrm{D}$ with a crucial role in calcium homeostasis and metabolism (Holick and Chen 2008). However, increasing evidence suggests that vitamin D and VDR play a pivotal role in the development of ovarian cancer. Epidemiological studies showed a reduced ovarian cancer risk in southern countries, indicating an association with the inhibition of vitamin D synthesis (Garland et al. 2006). Moreover, studies demonstrated an association between low circulating 25-hydroxyvitamin $\mathrm{D}$, a prehormone of vitamin $\mathrm{D}$, and a higher ovarian cancer incidence (Bakhru et al. 2010; Yin et al. 2011; Walentowicz-Sadlecka et al. 2012; Anastasi et al. 2016; Ong et al. 2016), while increased 25-hydroxyvitamin $D$ levels at diagnosis seem to be associated with longer overall survival in ovarian cancer patients (Webb et al. 2015). 25-Hydroxyvitamin D reduces proliferation and induces cell cycle arrest of ovarian cancer cells as well as in animal models (Jiang et al. 2003; Zhang et al. 2005; Thill et al. 2015). Furthermore, vitamin D is involved in epithelial-mesenchymal transition (EMT), a crucial process in cancerogenesis and tumor progression. Vitamin D decreases the expression of relevant transcription factors of EMT and thereby reduces migration and invasion of SKOV-3 cells. This might explain the effect of vitamin $\mathrm{D}$ on ovarian cancer in vitro and in vivo (Hou et al. 2016).

VDR is expressed in both benign and malignant ovarian tissues and influences the ovarian function by mediating estrogen biosynthesis and aromatase gene expression (Lurie et al. 2007). In vivo studies demonstrated that VDR-null mice show gonadal insufficiency and low aromatase activity.

Our findings are in line with previous reports showing that VDR expression is increased in ovarian cancer (VillenaHeinsen et al. 2002; Friedrich et al. 2003; Anderson et al. 2006; Agic et al. 2007). In 2010, Silvagno et al. analyzed the correlation between VDR expression and clinicopathological parameters, reporting predominantly cytoplasmic staining for VDR in ovarian cancer tissue (Silvagno et al. 2010). A comparable cytoplasmic staining pattern of VDR 


\section{a VDR - serous carcinoma}

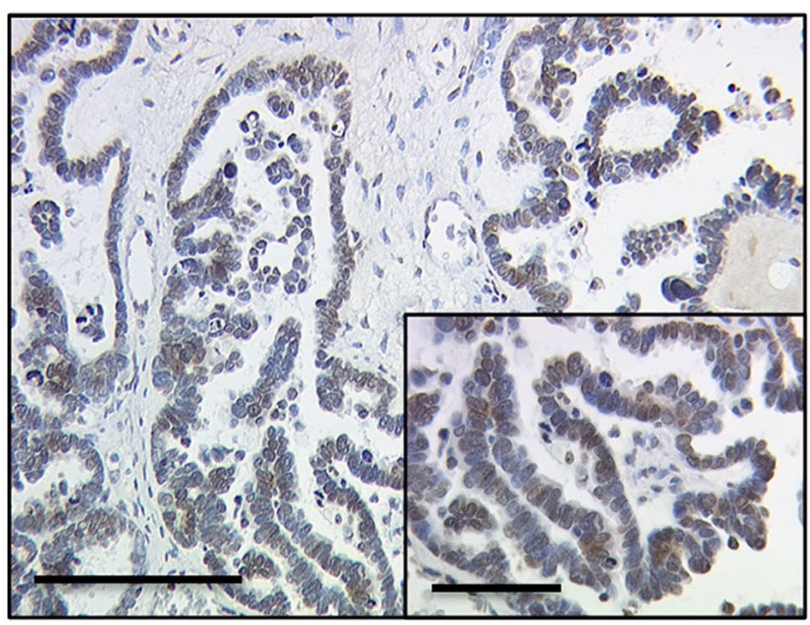

\section{c VDR - endometrioid carcinoma}

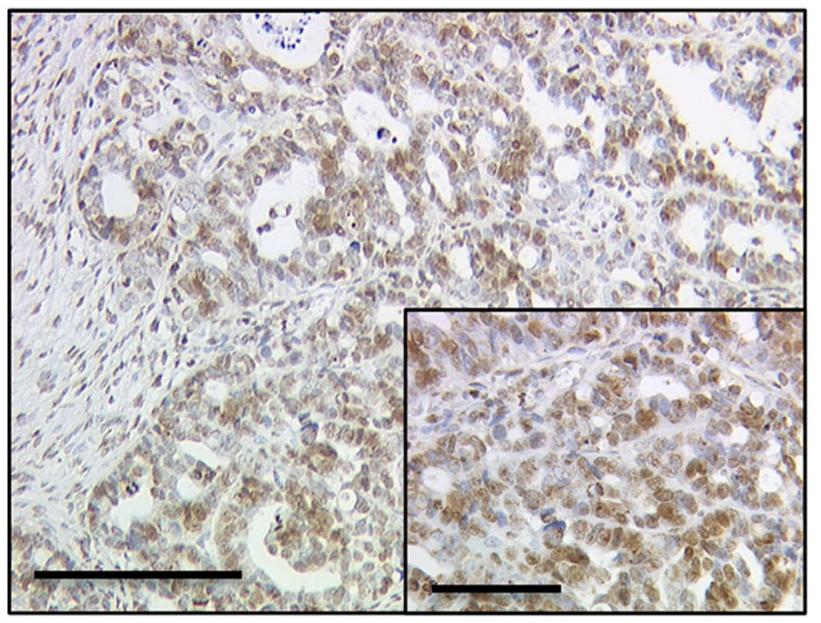

e VDR negative control - plazenta

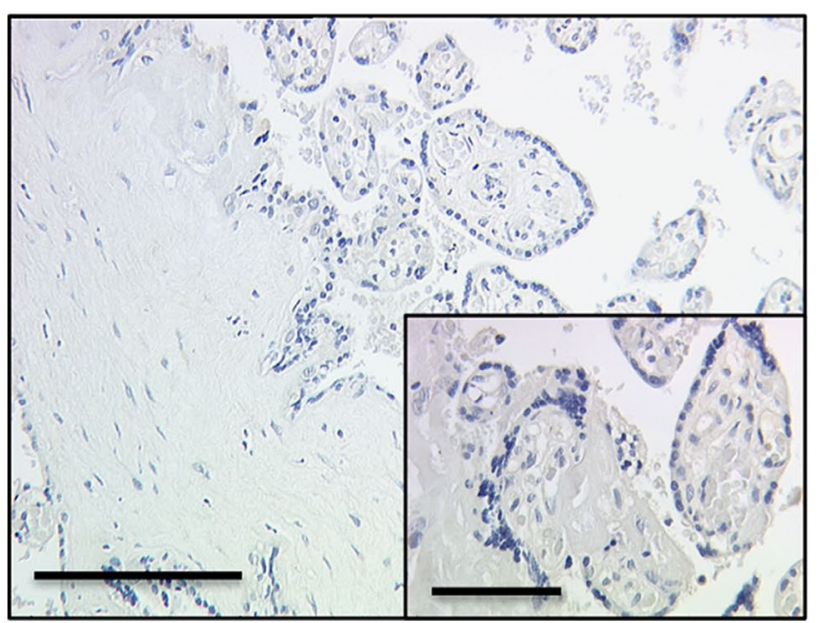

Fig. 1 Detection of VDR with immunohistochemistry: a high VDR cytoplasm staining (IRS $>2$ ) in ovarian cancer with serous, b clear cell, c endometrioid, (d) and mucinous histology. e VDR-negative

\section{b VDR - clear cell carcinoma}

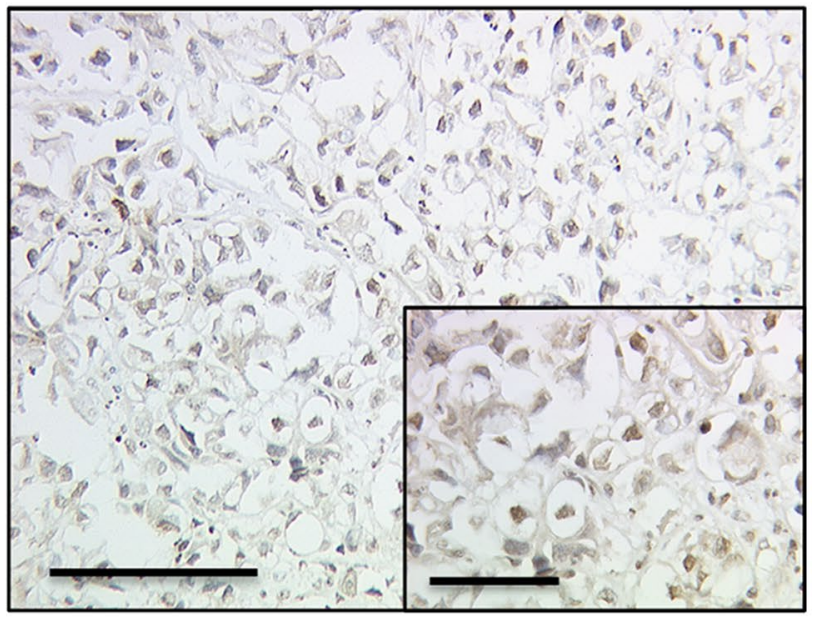

d VDR - mucinous carcinoma

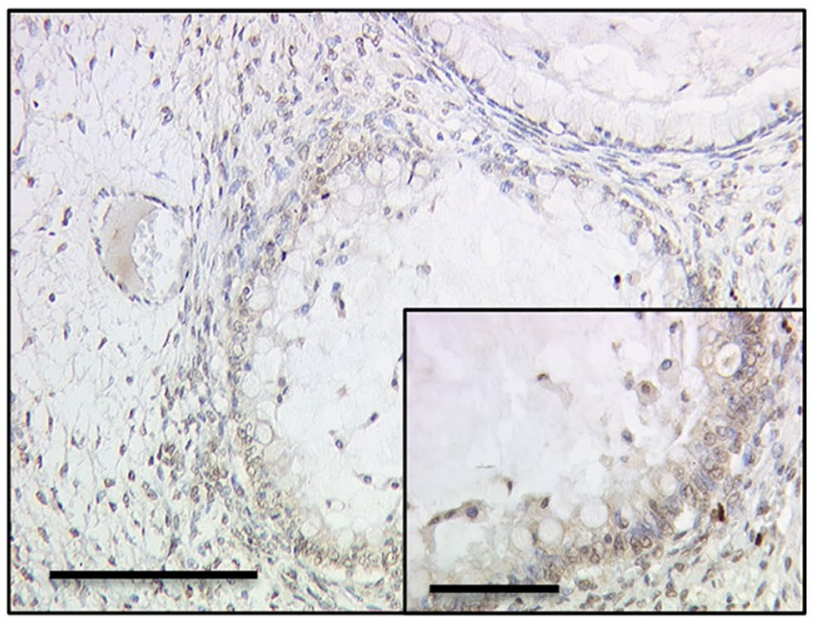

f VDR positive control - plazenta

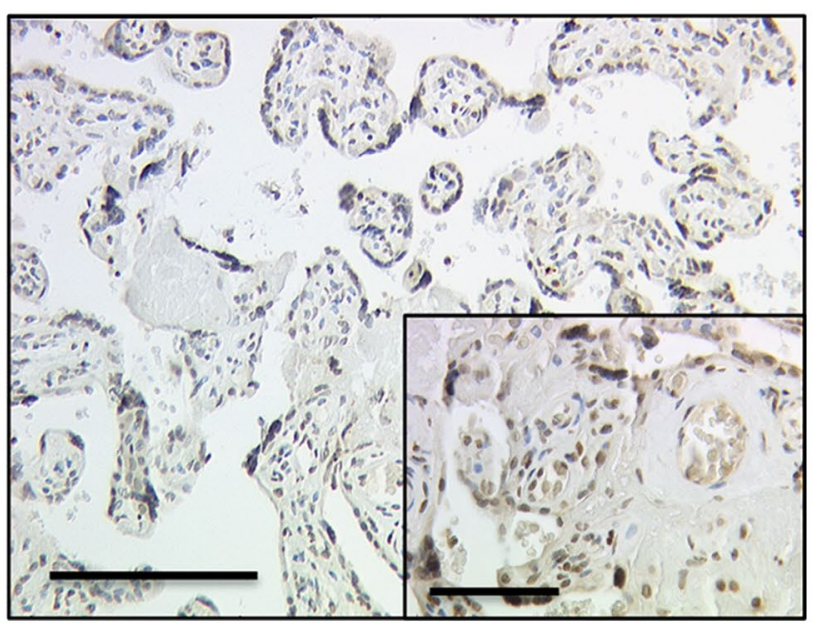

control (f) and positive control in human placenta tissue. $10 \times$ (scale bar $=200 \mu \mathrm{m})$ and $25 \times($ inserts, scale bar $=100 \mu \mathrm{m})$ magnification 
Table 2 Correlation between high cytoplasmic/ nuclear VDR expression and and clinicopathological data

\begin{tabular}{llllll}
\hline & \multicolumn{2}{l}{$\begin{array}{l}\text { Cytoplasmic VDR } \\
\text { expression }\end{array}$} & & \multicolumn{2}{l}{$\begin{array}{l}\text { Nuclear VDR } \\
\text { expression }\end{array}$} \\
\cline { 2 - 3 } \cline { 5 - 6 } Variables & $p$ & $\begin{array}{l}\text { Correlation } \\
\text { coefficient }\end{array}$ & & $\begin{array}{l}\text { Correlation } \\
\text { coefficient }\end{array}$ \\
\hline pT & 0.133 & 0.122 & & 0.653 & -0.037 \\
pN & $0.023^{*}$ & 0.236 & & 0.288 & 0.112 \\
FIGO & $0.013^{*}$ & 0.203 & & 0.620 & 0.041 \\
Grading & & & & & \\
Low-grade serous & 0.121 & -0.125 & & 0.065 & 0.150 \\
High-grade serous & $0.000^{* *}$ & 0.298 & & 0.155 & -0.116 \\
Clear cell, endometri- & $0.006^{* *}$ & -0.225 & & 0.883 & -0.012 \\
$\quad \begin{array}{l}\text { oid and mucinous-G1 } \\
\text { to G3 }\end{array}$ & & & & & \\
\hline
\end{tabular}

Clinicopathologic data and VDR expression were correlated to each other using Spearman's correlation analysis. Significant correlations are indicated by asterisks $(* p<0.05 ; * * p<0.01)$

$p$ two-tailed significance

was noticed in malignant melanoma, colon and vulvar cancer affecting tumor progression and prognosis (Matusiak et al. 2005; Salehin et al. 2012; Hutchinson et al. 2018). However, the functional effect of cytoplasmic VDR cannot be described by its nuclear signal cascade. Interestingly, VDR may mediate its molecular effect through two different pathways. While the classic nuclear pathway involves genes with promoters containing a vitamin $\mathrm{D}$ response element (VDRE) and consecutively regulates gene expression, the non-nuclear VDR-mediated pathway follows different mechanisms: VDR interacts with c-Src in the plasma membrane activating c-RAF and subsequently the MEK $1 / 2 /$ ERK $1 / 2$ pathway (Cordes et al. 2006; Buitrago and Boland 2010; Han et al. 2010; Doroudi et al. 2014). The extracellular signal-regulated kinase (ERK) pathway is one of the major signaling cascades of the MAPK signaling pathway, which plays a crucial role in cancerogenesis, including cell proliferation, differentiation, migration, apoptosis, and chemoresistance. Preclinical and early clinical studies underline the relevance of the ERK/MAPK pathway in ovarian cancer (Hsu et al. 2004; Bartholomeusz et al. 2006; Al-Ayoubi et al. 2008; Ohta et al. 2009; Vergara et al. 2012; Chang et al. 2012; Fujisawa et al. 2012; Wang et al. 2014; Su et al. 2016; Bai et al. 2016; Ma et al. 2018). In this context, high MAPK activity in tumors was associated with high cytoplasmic VDR expression, indicating an association of these pathways, which could lead to a crucial role of the non-nuclear VDR pathway in cancerogenesis. Hutchinson et al. showed a similar interaction in malignant melanoma (Hutchinson et al. 2018). Decreased nuclear and high cytoplasmic VDR expressions were associated with malignant progression in terms of dermal invasion and metastasis. Malignant melanomas that retained exclusive nuclear VDR at the tumor base

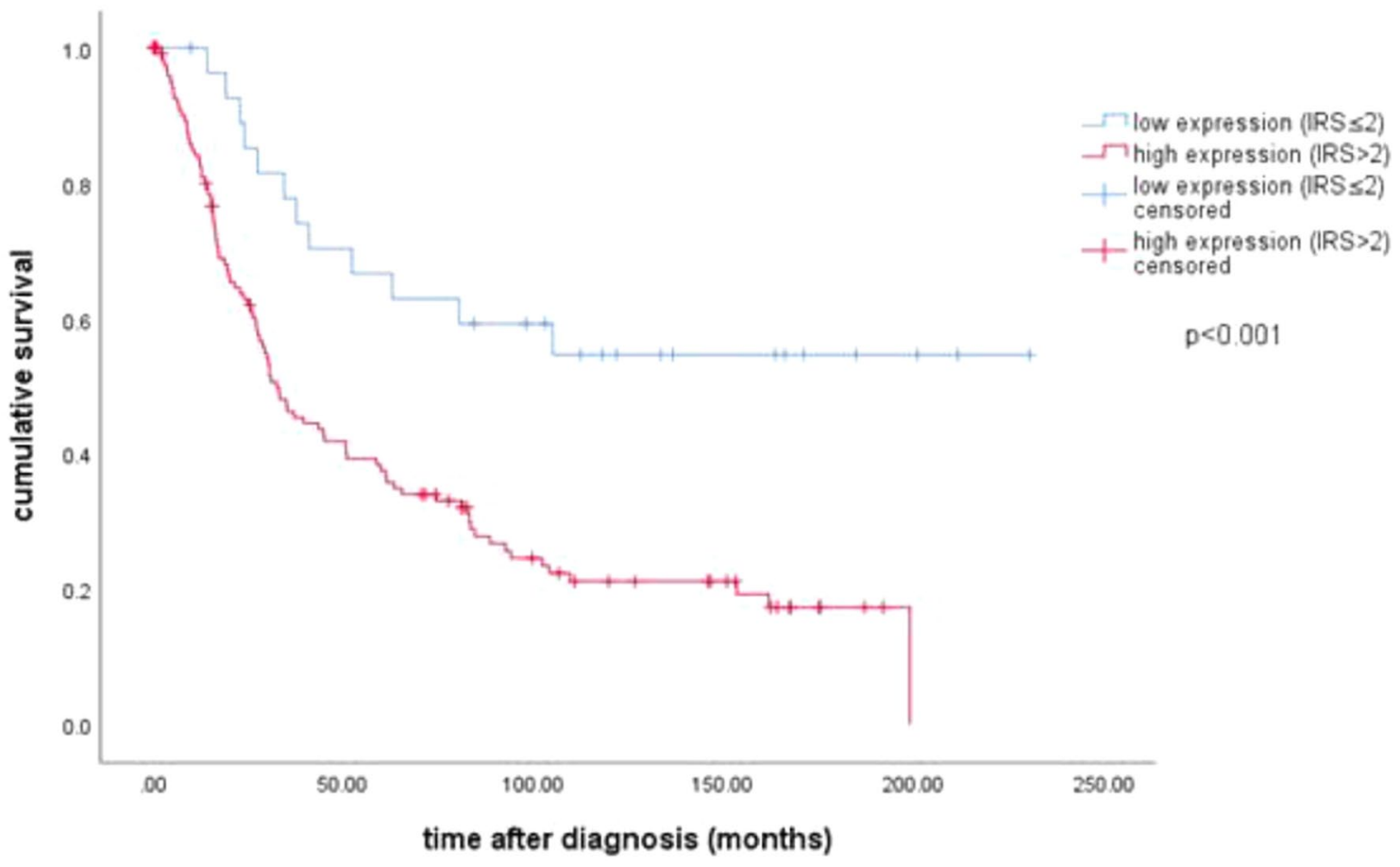

Fig. 2 Kaplan-Meier estimate of cytoplasmic VDR: High cytoplasmic VDR expression (IRS $>2$ ) was associated with impaired overall survival (HR 2.218, 32.5 months vs median not reached; $p<0.001$ ) 
Table 3 Multivariate analysis

\begin{tabular}{lcllll}
\hline Covariate & Coefficient & Hazard ratio & \multicolumn{2}{l}{$95 \%$ CI } & \multirow{2}{*}{$p$ value } \\
\cline { 5 - 6 } & & & Lower & Upper & \\
\hline Histology (serous vs other) & -0.037 & 0.963 & 0.637 & 1.457 & 0.86 \\
Grading (low vs high) & 0.472 & 1.604 & 1.158 & 2.138 & $0.000^{* *}$ \\
FIGO (I, II vs III, IV) & 0.666 & 1.947 & 1.409 & 2.690 & $0.000^{* *}$ \\
Patients' age ( $\leq 60$ vs $>60$ years) & 0.487 & 1.628 & 1.082 & 2.449 & $0.019^{*}$ \\
VDR cytoplasmic & 0.797 & 2.218 & 1.106 & 4.448 & $0.025^{*}$ \\
\hline
\end{tabular}

A multivariate Cox regression model was established to investigate independency of prognostic factors. Significant independent factors are indicated by asterisks $(* p<0.05 ; * * p<0.01)$

CI confidence interval

did not metastasize in this study. Furthermore, high MAPK activity in tumors expressing cytoplasmic VDR was associated with increased cell growth and worsened prognosis. In contrast, MAPK inhibition produced nuclear migration of VDR and decreased cell viability in vitro.

Inhibition of the MAPK pathway in EOC has been considered as a potential approach in subgroups of patients with specific histologic profiles, especially low-grade histology, although targeted therapies have so far failed to exhibit reliable therapeutic effects (Farley et al. 2013; Han et al. 2018; Fernandez et al. 2019). Thus defining subgroups of suitable patients for MAPK inhibition remains highly important.

Our data suggest cytoplasmic VDR as a potential predictive biomarker that might distinguish between tumors which are MAPK inhibitor sensitive and those which are not. Thus, cytoplasmatic VDR could be used to predict which patients profit from an MAPK inhibitor therapy.

Nevertheless, further studies are needed to prove our hypothesis as a basis for a better understanding of therapy in EOC subgroups.

Acknowledgements Open Access funding provided by Projekt DEAL. The authors are grateful to Mrs. Christina Kuhn for excellent technical assistance.

Author contributions $\mathrm{BC}, \mathrm{UJ}$, and FT conceived and designed the experiments. ED, CS, and UJ participated in immunohistochemistry analysis and performed the statistical analysis. DM and ES supervised immunohistochemistry as gynecologic pathologists and participated in immunohistochemistry analysis as well as in the design and coordination of the study. BC and FT wrote the paper. ED, YL, CS, TK, AH, SF, $\mathrm{AB}$, and $\mathrm{SM}$ revised the manuscript for important intellectual content. All authors analyzed and interpreted the results and read and approved the final manuscript.

Funding This research did not receive any specific grants from any funding agency in the public, commercial, or not-for-profit sector.

Data availability The datasets generated and/or analyzed during the current study are available from the corresponding author upon reasonable request.Code availability Data are available from the corresponding author on reasonable request.

\section{Compliance with ethical standards}

Conflict of interest Thomas Kolben holds stock of Roche AG and his relative is employed at Roche AG. Anna Hester has received a research grant from the "Walter Schulz" foundation and advisory board, speech honoraria, and travel expenses from Roche and Pfizer. Research support, advisory board, honoraria, and travel expenses from AstraZeneca, Clovis, Medac, MSD, Novartis, PharmaMar, Roche, Sensor Kinesis, Tesaro, and Teva have been received by Sven Mahner and others from AstraZeneca, Medac, PharmaMar, Roche, Tesaro by Fabian Trillsch. All other authors declare no conflict of interest. All the abovementioned companies did not influence the study design, data collection and analysis, decision to publish, or preparation of the manuscript.

Ethical approval This study was approved by the Ethics Committee of the Ludwig-Maximilians-University, Munich, Germany (approval numbers 227-09 and 18-392). The ovarian cancer specimens were obtained in clinically indicated surgeries and initially used for histopathological diagnostics. When the current study was performed, all diagnostic procedures were completed, and the patients' data were anonymized. The ethical principles adopted in the Declaration of Helsinki 1975 have been respected.

Consent for publication All authors have read the manuscript and agree to its publication.

Open Access This article is licensed under a Creative Commons Attribution 4.0 International License, which permits use, sharing, adaptation, distribution and reproduction in any medium or format, as long as you give appropriate credit to the original author(s) and the source, provide a link to the Creative Commons licence, and indicate if changes were made. The images or other third party material in this article are included in the article's Creative Commons licence, unless indicated otherwise in a credit line to the material. If material is not included in the article's Creative Commons licence and your intended use is not permitted by statutory regulation or exceeds the permitted use, you will need to obtain permission directly from the copyright holder. To view a copy of this licence, visit http://creativecommons.org/licenses/by/4.0/. 


\section{References}

Agic A, Xu H, Altgassen C et al (2007) Relative expression of 1,25-dihydroxyvitamin D3 receptor, vitamin D 1 $\alpha$-hydroxylase, vitamin D 24-hydroxylase, and vitamin D 25-hydroxylase in endometriosis and gynecologic cancers. Reprod Sci 14:486-497. https ://doi.org/10.1177/1933719107304565

Ahonen MH, Zhuang Y-H, Aine R et al (2000) Androgen receptor and vitamin $\mathrm{D}$ receptor in human ovarian cancer: growth stimulation and inhibition by ligands. Int $\mathrm{J}$ Cancer 86:40-46. https://doi.org/10.1002/(SICI)1097-0215(20000 401)86:1<40:AID-IJC6>3.0.CO;2-E

Al-Ayoubi A, Tarcsafalvi A, Zheng $\mathrm{H}$ et al (2008) ERK activation and nuclear signaling induced by the loss of cell/matrix adhesion stimulates anchorage-independent growth of ovarian cancer cells. J Cell Biochem 105:875-884. https://doi.org/10.1002/jcb.21889

Aletti GD, Gostout BS, Podratz KC, Cliby WA (2006) Ovarian cancer surgical resectability: relative impact of disease, patient status, and surgeon. Gynecol Oncol 100:33-37. https://doi.org/10.1016/j. ygyno.2005.07.123

Anastasi E, Capoccia D, Granato T et al (2016) Assessing the association between 25-Oh Vitamin D levels and roma score in a population of obese women. J Biol Regul Homeost Agents 30:1165-1171

Anderson MG, Nakane M, Ruan X et al (2006) Expression of VDR and CYP24A1 mRNA in human tumors. Cancer Chemother Pharmacol 57:234-240. https://doi.org/10.1007/s00280-005-0059-7

Bai RX, Wang WP, Zhao PW, Li CB (2016) Ghrelin attenuates the growth of HO-8910 ovarian cancer cells through the ERK pathway. Brazilian J Med Biol Res 49:e5043. https://doi. org/10.1590/1414-431X20155043

Bakhru A, Mallinger JB, Buckanovich RJ, Griggs JJ (2010) Casting light on 25-hydroxyvitamin D deficiency in ovarian cancer: a study from the NHANES. Gynecol Oncol 119:314-318. https:// doi.org/10.1016/j.ygyno.2010.07.006

Baldwin LA, Huang B, Miller RW et al (2012) Ten-year relative survival for epithelial ovarian cancer. Obstet Gynecol 120:612-618

Bartholomeusz C, Itamochi H, Nitta M et al (2006) Antitumor effect of E1A in ovarian cancer by cytoplasmic sequestration of activated ERK by PEA15. Oncogene 25:79-90. https://doi.org/10.1038/ sj.onc. 1209014

Buitrago C, Boland R (2010) Caveolae and caveolin-1 are implicated in $1 \alpha, 25(\mathrm{OH}) 2$-vitamin D3-dependent modulation of Src, MAPK cascades and VDR localization in skeletal muscle cells. J Steroid Biochem Mol Biol 121:169-175. https://doi.org/10.1016/j.jsbmb .2010.03.002

Chang M-C, Chen C-A, Chen P-J et al (2012) Mesothelin enhances invasion of ovarian cancer by inducing MMP-7 through MAPK/ ERK and JNK pathways. Biochem J 442:293-302. https://doi. org/10.1042/BJ20110282

Cordes T, Diesing D, Becker S et al (2006) Modulation of MAPK ERK1 and ERK2 in VDR-positive and -negative breast cancer cell lines. Anticancer Res 26:2749-2753

Dembo AJ, Davy M, Stenwig AE et al (1990) Prognostic factors in patients with stage I epithelial ovarian cancer. Obstet Gynecol 75:263-273

Deuster E, Jeschke U, Ye Y et al (2017) Vitamin D and VDR in gynecological cancers: a systematic review. Int J Mol Sci 18:2328. https://doi.org/10.3390/ijms18112328

Doroudi M, Chen J, Boyan BD, Schwartz Z (2014) New insights on membrane mediated effects of $1 \alpha, 25$-dihydroxy vitamin D3 signaling in the musculoskeletal system. Steroids 81:81-87

du Bois A, Reuss A, Pujade-Lauraine E et al (2009) Role of surgical outcome as prognostic factor in advanced epithelial ovarian cancer: A combined exploratory analysis of 3 prospectively randomized phase 3 multicenter trials. Cancer 115:1234-1244. https://doi.org/10.1002/cncr.24149

Farley J, Brady WE, Vathipadiekal V et al (2013) Selumetinib in women with recurrent low-grade serous carcinoma of the ovary or peritoneum: an open-label, single-arm, phase 2 study. Lancet Oncol 14:134-140. https://doi.org/10.1016/S1470-2045(12)70572 $-7$

Fernandez ML, Dawson A, Hoenisch J et al (2019) Markers of MEK inhibitor resistance in low-grade serous ovarian cancer: EGFR is a potential therapeutic target. Cancer Cell Int 19:10. https://doi. org/10.1186/s12935-019-0725-1

Fluss R, Faraggi D, Reiser B (2005) Estimation of the Youden Index and its associated cutoff point. Biometrical J 47:458-472. https:// doi.org/10.1002/bimj.200410135

Friedrich M, Rafi L, Mitschele T et al (2003) Analysis of the Vitamin D system in cervical carcinomas, breast cancer and ovarian cancer. In: Reichrath J, Tilgen W, Friedrich M (eds) Vitamin D analogs in cancer prevention and therapy. Springer, Heidelberg, pp 239-246

Fujisawa T, Joshi BH, Puri RK (2012) IL-13 regulates cancer invasion and metastasis through IL-13R $\alpha 2$ via ERK/AP-1 pathway in mouse model of human ovarian cancer. Int J Cancer 131:344-356. https://doi.org/10.1002/ijc.26366

Garland CF, Mohr SB, Gorham ED et al (2006) Role of Ultraviolet $B$ irradiance and Vitamin D in prevention of ovarian cancer. Am J Prev Med 31:512-514. https://doi.org/10.1016/j.amepr e.2006.08.018

Han S, Li T, Ellis E et al (2010) A novel bile acid-activated Vitamin D receptor signaling in human hepatocytes. Mol Endocrinol 24:1151-1164. https://doi.org/10.1210/me.2009-0482

Han C, Bellone S, Zammataro L et al (2018) Binimetinib (MEK162) in recurrent low-grade serous ovarian cancer resistant to chemotherapy and hormonal treatment. Gynecol Oncol Rep 25:41-44. https://doi.org/10.1016/j.gore.2018.05.011

Holick MF, Chen TC (1086S) Vitamin D deficiency: a worldwide problem with health consequences. Am J Clin Nutr 87:1080S-1086S. https://doi.org/10.1093/ajcn/87.4.1080S

Hou Y-F, Gao S-H, Wang P et al (2016) $1 \alpha, 25(\mathrm{OH})_{2} \mathrm{D}_{3}$ suppresses the migration of ovarian cancer SKOV-3 cells through the inhibition of epithelial-mesenchymal transition. Int J Mol Sci 17:1285. https ://doi.org/10.3390/ijms17081285

Hsu C-Y, Bristow R, Cha MS et al (2004) Characterization of active mitogen-activated protein kinase in ovarian serous carcinomas. Clin Cancer Res 10:6432-6436. https://doi.org/10.1158/10780432.CCR-04-0893

Hutchinson PE, Halsall JA, Popovici S et al (2018) Compromised vitamin D receptor signalling in malignant melanoma is associated with tumour progression and mitogen-activated protein kinase activity. Melanoma Res 28:410-422

Jiang F, Li P, Fornace AJ et al (2003) G2/M arrest by 1,25-dihydroxyvitamin D3 in ovarian cancer cells mediated through the induction of GADD45 via an exonic enhancer. J Biol Chem 278:48030 48040. https://doi.org/10.1074/jbc.M308430200

Kossaï M, Leary A, Scoazec J-Y, Genestie C (2018) Ovarian cancer: a heterogeneous disease. Pathobiology 85:41-49. https://doi. org/10.1159/000479006

Lurie G, Wilkens LR, Thompson PJ et al (2007) Vitamin D receptor; gene polymorphisms and epithelial ovarian cancer risk. Cancer Epidemiol Biomarkers Prev 16:2566-2571. https://doi. org/10.1158/1055-9965.EPI-07-0753

Ma Y, Xu Y, Li L (2018) SPARCL1 suppresses the proliferation and migration of human ovarian cancer cells via the MEK/ERK signaling. Exp Ther Med 16:3195-3201. https://doi.org/10.3892/ etm. 2018.6575

Matusiak D, Murillo G, Carroll RE et al (2005) Expression of Vitamin $\mathrm{D}$ receptor and 25-hydroxyvitamin D3-1 $\alpha$-hydroxylase in normal 
and malignant human colon. Cancer Epidemiol Biomarkers Prev 14:2370-2376. https://doi.org/10.1158/1055-9965.EPI-05-0257

Nakas CT, Alonzo TA, Yiannoutsos CT (2010) Accuracy and cut-off point selection in three-class classification problems using a generalization of the Youden index. Stat Med 29:2946-2955. https:// doi.org/10.1002/sim.4044

Ohta T, Isobe M, Takahashi T et al (2009) The Akt and ERK activation by platinum-based chemotherapy in ovarian cancer is associated with favorable patient outcome. Anticancer Res 29:4639-4647

Ong J-S, Cuellar-Partida G, Lu Y et al (2016) Association of vitamin $\mathrm{D}$ levels and risk of ovarian cancer: a Mendelian randomization study. Int J Epidemiol 45:1619-1630. https://doi.org/10.1093/ije/ dyw 207

Perkins NJ, Schisterman EF (2006) The inconsistency of "optimal" cutpoints obtained using two criteria based on the receiver operating characteristic curve. Am J Epidemiol 163:670-675. https:// doi.org/10.1093/aje/kwj063

Salehin D, Haugk C, Thill M et al (2012) Vitamin D receptor expression in patients with vulvar cancer. Anticancer Res 32:283-289

Scholz C, Heublein S, Lenhard M et al (2012) Glycodelin A is a prognostic marker to predict poor outcome in advanced stage ovarian cancer patients. BMC Res Notes 5:551. https://doi. org/10.1186/1756-0500-5-551

Siegel RL, Miller KD, Jemal A (2019) Cancer statistics, 2019. CA Cancer J Clin 69:7-34. https://doi.org/10.3322/caac.21551

Silvagno F, Poma CB, Realmuto C et al (2010) Analysis of vitamin D receptor expression and clinical correlations in patients with ovarian cancer. Gynecol Oncol 119:121-124. https://doi.org/10.1016/j. ygyno.2010.06.008

Su S, Lin X, Ding N et al (2016) Effects of PARP-1 inhibitor and ERK inhibitor on epithelial mesenchymal transitions of the ovarian cancer SKOV3 cells. Pharmacol Rep 68:1225-1229. https://doi. org/10.1016/j.pharep.2016.08.001

Thill M, Woeste A, Reichert K et al (2015) Vitamin D inhibits ovarian cancer cell line proliferation in combination with celecoxib and suppresses cyclooxygenase- 2 expression. Anticancer Res 35:1197-1203

Valdivielso JM, Fernandez E (2006) Vitamin D receptor polymorphisms and diseases. Clin Chim Acta 371:1-12. https://doi. org/10.1016/j.cca.2006.02.016
Vergara D, Simeone P, Toraldo D et al (2012) Resveratrol downregulates Akt/GSK and ERK signalling pathways in OVCAR-3 ovarian cancer cells. Mol Biosyst 8:1078-1087. https://doi.org/10.1039/ $\mathrm{C} 2 \mathrm{MB} 05486 \mathrm{H}$

Vergote I, De Brabanter J, Fyles A et al (2001) Prognostic importance of degree of differentiation and cyst rupture in stage I invasive epithelial ovarian carcinoma. Lancet 357:176-182. https://doi. org/10.1016/S0140-6736(00)03590-X

Villena-Heinsen C, Meyberg R, Axt-Fliedner R et al (2002) Immunohistochemical analysis of 1,25-dihydroxyvitamin-D3-receptors, estrogen and progesterone receptors and Ki-67 in ovarian carcinoma. Anticancer Res 22:2261-2267

Walentowicz-Sadlecka M, Grabiec M, Sadlecki P et al (2012) 25(OH) D3 in patients with ovarian cancer and its correlation with survival. Clin Biochem 45:1568-1572. https://doi.org/10.1016/j.clinb iochem.2012.07.110

Wang W, Ren F, Wu Q et al (2014) MicroRNA-497 suppresses angiogenesis by targeting vascular endothelial growth factor A through the PI3K/AKT and MAPK/ERK pathways in ovarian cancer. Oncol Rep 32:2127-2133. https://doi.org/10.3892/or.2014.3439

Webb PM, de Fazio A, Protani MM et al (2015) Circulating 25-hydroxyvitamin D and survival in women with ovarian cancer. Am J Clin Nutr 102:109-114. https://doi.org/10.3945/ajen.114.102681

Yin L, Grandi N, Raum E et al (2011) Meta-analysis: circulating vitamin D and ovarian cancer risk. Gynecol Oncol 121:369-375. https ://doi.org/10.1016/j.ygyno.2011.01.023

Youden WJ (1950) Index for rating diagnostic tests. Cancer 3:32-35. https://doi.org/10.1002/1097-0142(1950)3:1<32:AID-CNCR2 $820030106>3.0 . \mathrm{CO} ; 2-3$

Zhang X, Jiang F, Li P et al (2005) Growth suppression of ovarian cancer xenografts in nude mice by Vitamin D analogue EB1089. Clin Cancer Res 11:323-328

Publisher's Note Springer Nature remains neutral with regard to jurisdictional claims in published maps and institutional affiliations. 